\title{
KORELASI ANTARA LINGKAR DADA, PANJANG BADAN DAN TINGGI GUMBA TERHADAP VOLUME SEMEN DAN KONSENTRASI SPERMATOZOA SAPI MADURA
}

\section{THE CORRELATION BETWEEN HEART GIRTH, BODY LENGTH AND WITHER'S HEIGHT WITH SEMEN VOLUME AND SPERM CONCENTRATIONOF MADURA BULLS}

\author{
Dilla Aranda Mayola ${ }^{1)}$, *Rimayanti ${ }^{2)}$, Sunaryo Hadi Warsito ${ }^{3)}$, Suzanita Utama ${ }^{4}$, \\ Hana Eliyani ${ }^{5}$, Erma Safitri ${ }^{6}$ ) \\ ${ }^{1)}$ Student, ${ }^{2,4,6}$ Departement of Veterinary Reproduction, ${ }^{3)}$ Departement of Animal Husbandry, \\ ${ }^{5}$ Departement of Veterinary Anatomy \\ Faculty of Veterinary Medicine, Airlangga University \\ *Corresponding author: email: rima_irmansyah@yahoo.com; dillamayola1122@gmail.com
}

\begin{abstract}
The aim of this research was to know the correlation between heart girth, body length, and wither's height with semen volume and sperm concentration of Madura Bulls. Ten Madura bulls aged three to four years from Madura were measured. Variables observed were heart girth, body length, wither's height, semen volume and sperm concentration. Data were analyzed by multiple linear regression analysis. The result of this research showed that there was no correlation between heart girth, body length, and wither's height with semen volume $\mathrm{Y}=$ $25,212+0,190 X_{1}+(-0,131) X_{2}+0,136 X_{3}$, so as there was no correlation between heart girth, body length and wither's height with sperm concentration $\mathrm{Y}=8739,559+(-36,663) \mathrm{X}_{1}+(-$ $19,714) X_{2}+6,2960 X_{3}$. And than was no correlation between semen volume and sperm concentration $\mathrm{Y}=7,303+(-0,002) \mathrm{X}_{1}$.
\end{abstract}

Keywords : Madura bulls, correlation, heart girth, semen volume, sperm concentration.

\section{Pendahuluan}

Madura merupakan wilayah yang memiliki kontribusi besar terhadap populasi sapi potong di Jawa Timur yakni sekitar (21\%). Madura ditetapkan sebagai wilayah tertutup, yaitu wilayah yang dilarang untuk dilakukannya perkawinan silang dengan pejantan ternak sapi potong yang berasal dari luar Madura. Hal ini bertujuan untuk mempertahankan kemurnian sapi Madura sebagai salah satu plasma nutfah sapi lokal Indonesia (Siswijono dkk., 2013).

Sapi Madura merupakan salah satu bangsa sapi di Indonesia yang memiliki berbagai keunggulan genetik selain itu juga memiliki kinerja reproduksi yang lebih baik dibandingkan dengan Bos taurus, lebih tahan terhadap panas dan penyakit caplak (Hartatik dkk., 2009). Keberadaan sapi Madura di Pulau asalnya tidak hanya dipergunakan sebagai ternak potong saja. Adat istiadat, budaya dan kesenian yang sangat dilestarikan di pulau ini menjadikan sapi Madura sebagai lambang masyarakat Madura terutama dalam kebudayaan serta kesenian (Wulandari, 2015).

Inseminasi buatan (IB) merupakan salah satu teknologi yang digunakan untuk meningkatkan populasi dan produksi ternak secara kuantitatif dan kualitatif dengan membuat semen beku yang berasal dari pejantan unggul (Toelihere, 1993). Menurut Budi dan Setiadi (2004), perbaikan mutu genetik sapi Madura melalui program perkawinan secara Inseminasi Buatan memiliki peluang yang cukup besar untuk meningkatkan mutu genetik sapi Madura.

Hingga saat ini perkembangan program perkawinan secara Inseminasi Buatan di kalangan peternak Madura masih sangat lambat, serta tidak didukung oleh ketersediaan pejantan unggul sapi Madura di Balai Inseminasi Buatan (BIB) atau Dinas Peternakan di pulau Madura yang belum memadai. Salah satu kunci penting keberhasilan program perkawinan dengan inse- 
minasi buatan adalah tersedianya sapi pejantan dengan kualitas semen unggul yang dapat diketahui dengan melakukan pemeriksaan makroskopis dan mikroskopis semen (Sumeidiana, 2009).

Penilaian terhadap kualitas mikroskopis semen dilakukan di laboratorium apabila tempat penampungan dan laboratorium berjarak dekat. Namun apabila jarak tempat penampungan semen dan laboratorium pengujian jauh, maka penilaian kualitas mikroskopis semen diperlukan alat-alat yang harus dibawa di lokasi penampungan. Kerumitan prosedur tahapan pelaksanaan seleksi tersebut merupakan suatu kendala yang menyebabkan pelaksanaan seleksi tidak efisien karena membutuhkan waktu pengujian serta seleksi menjadi tidak praktis (Saputra dkk, 2017), sehingga untuk mengetahui kualitas semen pejantan yang baik diperlukan teknik lain yaitu dengan melalui ukuran lingkar dada, panjang badan dan tinggi gumba yang diperkirakan memiliki hubungan yang positif terhadap kualitas semen pejantan sapi Madura. Keadaan ini tampaknya sesuai dengan pendapat Frandson (1992) dan Wijaya (1992) bahwa kualitas semen dari seekor pejantan unggul dapat dipengaruhi oleh beberapa faktor, antara lain umur, bangsa dan ukuran tubuh. Ukuran tubuh seperti lingkar dada, panjang badan dan tinggi gumba dapat digunakan untuk menaksir berat badan sapi berdasarkan rumus Schoorl, Lambourne, Winter dan Denmark (Ni'am dkk., 2012). Berat badan yang dapat diwakili dengan pengukuran lingkar dada dapat digunakan untuk mengetahui tingkat pertumbuhan hewan termasuk pertumbuhan badan dan reproduksinya (Fourie dkk., 2002).

Berdasarkan uraian di atas, maka perlu dilakukan penelitian untuk mengetahui adanya korelasi antara lingkar dada, panjang badan dan tinggi gumba terhadap volume dan konsentrasi spermatozoa sapi Madura. Sehingga nantinya pelaksanaan seleksi terhadap kualitas semen yang dimiliki pejantan dapat dilakukan hanya dengan melalui ukuran lingkar dada, panjang badan dan tinggi gumba sebagai standar dalam seleksi yang digunakan untuk mengetahui kualitas semen pada pejantan sapi Madura secara langsung.

\section{Metode Penelitian}

Hewan penelitian yang digunakan adalah 10 ekor sapi Madura jantan berumur 3 sampai 4 tahun dan berat badan berkisar $250 \mathrm{~kg}$ sampai $350 \mathrm{~kg}$ dalam kondisi sehat. Sapi Madura yang digunakan milik UPT Pembibitan Ternak dan Kesehatan Hewan Madura Pamekasan. Bahan penelitian yang digunakan dalam penelitian ini terdiri dari vaselin, $\mathrm{NaCl}$ fisiologis, air panas dan kapas. Alat yang digunakan dalam penelitian ini adalah pita ukur merk Animeter yang digunakan untuk mengukur lingkar dada, tongkat ukur yang digunakan untuk mengukur panjang badan dan tinggi gumba, spektrofotometer merk Minitube untuk mengetahui konsentrasi spermatozoa, kuvet, vagina buatan khusus untuk sapi lengkap dengan selongsong karet dan tabung gelas berskala untuk menampung semen dan pipet.

\section{Analisis Data}

Data yang diperoleh yaitu lingkar dada, panjang badan dan tinggi gumba, serta volume semen dan konsentrasi spermatozoa disajikan dalam bentuk tabel kemudian dianalisis dengan regresi linear berganda dan korelasi menggunakan program SPSS.

\section{Hasil Dan Pembahasan}

Hasil pengukuran sapi Madura dalam penelitian ini menunjukkan lingkar dada $(160,60 \pm 7,24) \mathrm{cm}$; panjang badan $(132,65$ $\pm 5,61) \mathrm{cm}$; tinggi gumba $(125,45 \pm 4,47)$ $\mathrm{cm}$; volume semen $(5,05 \pm 2,32) \mathrm{ml}$ dan konsentrasi spermatozoa $\quad(1026,30 \quad \pm$ 374,92) juta/ml.

\section{A. Hasil Analisis Korelasi antara Ling- kar Dada, Panjang Badan dan Tinggi Gumba dengan Volume Se- men}

Hasil analisis regresi linear berganda dan korelasi menunjukkan bahwa antara volume semen tidak berkorelasi nyata dengan lingkar dada $(\mathrm{p}=0,262)$, panjang badan $(\mathrm{p}=0,451)$ dan tinggi gumba $(\mathrm{p}=$ $0,554)$ dan nilai konstanta sebesar $-25,212$ sehingga dirumuskan: $Y=-25,212+0,190$ $X_{1}-0,131 X_{2}+0,136 X_{3}$. Hasil korelasi ini dapat diartikan bahwa setiap kenaikan satu satuan lingkar dada, panjang badan dan tinggi gumba tidak diikuti dengan pe- 
ningkatan volume semen. Hal ini mungkin dipengaruhi oleh musim. Penelitian ini dilaksanakan pada bulan Januari dengan volume semen 5,05 $\mathrm{ml}$ dimana pada bulan tersebut sedang mengalami musim hujan. Curah hujan yang tinggi menyebabkan sapi tidak merasa haus sehingga konsumsi air menurun. Apabila konsumsi air menurun maka sekresi dari kelenjar asesorius akan menurun yang diikuti dengan penurunan plasma semen sehingga mempengaruhi volume semen. Hal ini sesuai dengan pendapat Khairi, dkk (2014) bahwa semakin tinggi curah hujan maka volume semen yang dihasilkan semakin rendah, begitu juga sebaliknya semakin rendah curah hujan volume semen yang dihasilkan semakin tinggi, sedangkan menurut Koivisto et al., (2009) bahwa musim dapat berpengaruh terhadap kualitas semen lebih dari $2 \%$.

Nutrisi makanan yang rendah juga menjadi faktor yang mempengaruhi tidak adanya korelasi antara lingkar dada, panjang badan dan tinggi gumba terhadap volume semen. Menurut Hariadi, dkk (2011) kekurangan pakan menyebabkan penurunan sekresi testosteron diikuti penurunan kelenjar asesoris sehingga plasma semen yang dihasilkan menurun. Apabila plasma semen menurun maka akan mempengaruhi volume semen. Seekor sapi harus mendapatkan cukup pakan yang meliputi hijauan $10 \%$ dari BB dan juga konsentrat $1-2 \%$ dari BB. Faktor lain yang mungkin mempengaruhi yaitu lingkungan. Pada saat pengambilan semen sapi terdapat banyak orang disekitarnya, jumlah orang yang terlalu banyak akan mempengaruhi kondisi sapi menjadi stress sehingga produksi semen tidak maksimal. Hal ini sesuai dengan penelitian Erlisa (2013) yang menunjukkan bahwa saat pengambilan semen diharapkan hewan pada kondisi yang tenang agar produksi semen yang dihasilkan maksimal selain itu jumlah orang diharapkan tidak terlalu banyak karena dapat mempengaruhi kondisi hewan menjadi stres. Rata-rata volume semen sapi adalah $4 \mathrm{ml}$ (3-7 ml), selain itu sapi mempunyai volume semen rendah (Susilowati dkk., 2010).

\section{B. Hasil Analisis Korelasi antara Ling- kar Dada, Panjang Badan dan Tinggi}

\section{Gumba dengan Konsentrasi Sperma- tozoa}

Hasil analisis regresi linear berganda dan korelasi menunjukkan bahwa antara konsentrasi spermatozoa tidak berkorelasi nyata dengan lingkar dada $(\mathrm{p}=0,062)$, panjang badan $(\mathrm{p}=0,288)$ dan tinggi gumba $(\mathrm{p}=0,791)$ dan nilai konstanta sebesar 8739,559 sehingga dirumuskan: $\mathrm{Y}$ $=8739,559+(-36,663) \mathrm{X}_{1}+(-19,714) \mathrm{X}_{2}+$ $6,2960 \mathrm{X}_{3}$. Hasil korelasi ini dapat diartikan bahwa setiap kenaikan satu satuan lingkar dada, panjang badan dan tinggi gumba tidak diikuti dengan peningkatan konsentrasi spermatozoa. Hal ini mungkin disebabkan oleh pakan. Nutrisi makanan yang terkandung didalam hijauan, tepung ikan dan konsentrat yang diberikan untuk pakan sapi masih rendah, hal ini terbukti setelah dilakukan uji analisis proksimat yang didapatkan hasil belum sesuai dengan SNI. Kurangnya pakan akan menyebabkan hipofungsi kelenjar hipofisa anterior diikuti menurunnya sekresi hormon gonadotropin (FSH dan LH) sehingga hormon testosteron menurun. Apabila hormon testosteron menurun maka proses spermatogenesis akan menurun dan akan menyebabkan menurunnya jumlah spermatozoa yang dihasilkan (Hariadi dkk., 2011). Sesuai dengan pendapat Djanuar (1985) bahwa hormon testosteron yang tinggi dapat meningkatkan konsentrasi spermatozoa dalam semen dan apabila hormon testosteron rendah maka dapat menurunkan konsentrasi spermatozoa. Fungsi hormon testosteron memegang peranan penting didalam proses spermatogenesis yaitu pada saat mulai terjadi aktivitas organ reproduksi jantan yang berupa aktivitas proses pembentukan spermatozoa.

Faktor lain yang mungkin mempengaruhi yaitu lingkungan. Apabila jumlah orang yang terlalu banyak pada saat pengambilan semen sapi, maka akan mempengaruhi kondisi sapi menjadi stress sehingga produksi semen tidak maksimal. Pada saat pengambilan semen diharapkan hewan pada kondisi yang tenang agar produksi semen yang dihasilkan maksimal selain itu jumlah orang diharapkan tidak terlalu banyak karena dapat mempengaruhi kondisi hewan menjadi stress (Erlisa, 2013). 
Jumlah spermatozoa setiap unit volume semen sapi bervariasi mulai dari nol sampai tiga miliyar $\left(3000 \times 10^{6}\right)$ spermatozoa setiap $\mathrm{ml}$. Konsentrasi spermatozoa yang berderajat tinggi biasanya berkisar dari $2000 \times 10^{6}$ sampai $2200 \times 10^{6}$ spermatozoa (Salisbury dan Vandenmark, 1985). Sesuai dengan pendapat Djanuar (1985) yang menyatakan bahwa konsentrasi pada umumnya sejalan dengan perkembangan seksual dan kedewasaan ternak, kualitas pakan, pengaruh kesehatan alat reproduksi, dan besar testis, selain itu dipengaruhi juga oleh faktor keturunan, musim, dan perbedaan tempat geografis.

\section{Hasil Analisis Korelasi antara Volume Semen dengan Konsentrasi Spermatozoa}

Hasil analisis regresi linear berganda dan korelasi menunjukkan bahwa volume semen terhadap konsentrasi spermatozoa tidak berkorelasi nyata, masing-masing dengan angka signifikasi 0,316 dan nilai konstanta sebesar 7,303 sehingga dirumuskan: $\mathrm{Y}=7,303+(-0,002) \mathrm{X}_{1}$. Hasil korelasi ini tidak signifikan artinya setiap kenaikan satu satuan konsentrasi spermatozoa tidak diikuti dengan peningkatan volume semen. Hal ini mungkin terjadi karena semen sapi terdiri dari dua bagian yaitu spermatozoa dan plasma semen. Apabila volume semen mengalami peningkatan belum tentu diikuti juga peningkatan jumlah spermatozoa dimungkinkan jumlah plasma semen yang meningkat dan bertambah banyak sedangkan spermatozoannya tidak, sesuai dengan pendapat Toelihere (1993) yang menyatakan sapi cenderung mempunyai volume semen dengan konsentrasi spermatozoa yang rendah dan plasma semen yang tinggi atau sebaliknya. Volume rendah tidak merugikan, tetapi bila disertai dengan konsentrasi spermatozoa yang rendah akan membatasi jumlah spermatozoa yang tersedia.

Volume semen yang rendah dipengaruhi oleh musim. Pada saat penelitian terjadi hujan sehingga konsumsi air menurun diikuti menurunnya sekresi kelenjar termasuk kelenjar asesorius pada sapi. Apabila sekresi dari kelenjar asesorius menurun maka menyebabkan menurunnya plasma semen. Curah hujan mempengaruhi volume semen, apabila curah hujan tinggi maka volume semen yang dihasilkan semakin rendah (Khairi dkk, 2014). Demikian pula konsentrasi spermatozoa yang mungkin disebabkan oleh pakan, kurangnya pakan akan menyebabkan hormon testosteron menurun. Apabila hormon testosteron menurun maka proses spermatogenesis akan menurun sehingga menyebabkan menurunnya jumlah spermatozoa yang dihasilkan (Hariadi dkk., 2011). Menurut pendapat Djanuar (1985) bahwa hormon testosteron yang tinggi dapat meningkatkan konsentrasi spermatozoa dalam semen dan apabila hormon testosteron rendah maka dapat menurunkan konsentrasi spermatozoa dan selain itu juga ada faktor lingkungan.

\section{Kesimpulan}

Berdasarkan hasil yang telah diteliti, maka dapat disimpulkan bahwa Lingkar dada, panjang badan dan tinggi gumba tidak memiliki korelasi terhadap volume semen sapi Madura, demikian pula lingkar dada, panjang badan dan tinggi gumba juga tidak memiliki korelasi terhadap konsentrasi spermatozoa sapi Madura selain itu volume semen tidak memiliki korelasi terhadap konsentrasi spermatozoa sapi Madura.

\section{Daftar Pustaka}

Budi, S.W. dan B. Setiadi. 2004. Potensi dan Keragaman Sumberdaya Ge-netik Sapi Madura. Lokakarya Sapi Potong. 45.

Djanuar, 1985. Fisiologi Reproduksi dan Inseminasi Buatan pada Sapi. Gadjah Mada University Press. Yogyakarta. 33-34.

Erlisa, L. 2013. Korelasi Antara Berat Badan dengan Panjang Badan, Tinggi Badan, Lingkar Dada, Lingkar Scrotum, Volume dan Kualitas Semen pada Kambing Peranakan Ettawah (PE) [Skripsi]. Fakultas Kedokteran Hewan. Universitas Airlangga. Surabaya.

Fourie, PJ., FWC. Neser, JJ. Olivier and C. Van Der Westhuesin. 2002. Relationship Between Production Performance, Visual Apprasial and Body Measurements of Young Dorper Rams. South African Journal of Animal Science. South Africa. 32: 4. 
Frandson, R.D. 1992. Anatomi dan Fisiologi Ternak Edisi ke-4. Diterjemahkan oleh Srigandono, B dan Praseno, K. Gadjah Mada Univer-sity Press. Yogyakarta. 34-40.

Hariadi, H.M, H.S, Hardjopranjoto, Wurlina, H.A. Hermadi, B.Utomo, Rimayanti, I.N. Triana, H. Ratnani. 2011. Buku Ajar Ilmu Kemajiran Pada Ternak. Airlangga University Press. Surabaya. 63.

Hartatik, T., A.M, Dhany., S.M.W, Tri., dan B. Endang. 2009. Karakteristik dan Kinerja Induk Sapi Silangan Limosin-Madura dan Madura di Kabupaten Sumenep dan Pamekasan. Buletin Peternakan. 33: 143-147.

Khairi, F., A. Muktiani dan Y. S. Ondho. 2014. Pengaruh Suplementasi Vitamin E, Mineral Selenium dan Zink terhadap Konsumsi Nutrien, Produksi dan Kualitas Semen Sapi Simmental. Agripet. 14: 6-16.

Koivisto M.B., M. T. Costa, S. H. Perri and W. R. R. Vicente. 2009. The Effect of Season on Semen Characteristics and Freezability in Bos Indicus and Bos Taurus Bulls in the Southeastern Region of Brazil. Reproduction Domestic Animal. 44: 587-592.

Ni'am, H.U.M., Purnomoadi, A. dan Dartosukarno, S. 2012. Hubungan Antara Ukuran-Ukuran Tubuh Dengan Bobot Badan Sapi Bali Betina Pada Berbagai Kelompok Umur. Animal Agriculture Journal. 1: 541 556.
Salisburry, G.W. dan N.L. Vandemark. 1985. Fisiologi Reproduksi dan Inseminasi Buatan pada Sapi. Gajah Mada University Press. 200-222, 826.

Saputra, D.J., M. N. Ihsan dan N. Isnaini. 2017. Korelasi antara Lingkar Skrotum dengan Volume, Konsentrasi dan Motilitas Spermatozoa Pejantan Sapi Bali. Universitas Brawijaya.

Siswijono, S.B., V.M.A. Nurgiartiningsih, dan Hermanto. 2013. Pengembangan Model Kelembagaan Konservasi Sapi Madura. Universitas Brawijaya.

Sumeidiana. I.K. 2009. Pengaruh Lingkar Scrotum dan Volume Testis terhadap Volume Semen dan Konsentrasi Sperma Pejantan Simental, Limousine dan Brahman. Seminar Nasional Ternologi Peternakan dan Veteriner 2009. Fakultas Peternakan Universitas Diponegoro, Semarang. 71.

Toelihere, M.R. 1993. Inseminasi Buatan pada Ternak. Cetakan 3. Angkasa. Bandung. 48-50,55-89.

Wijaya, I.N.S. 1992. Pengaruh Musim dan Umur Tehadap Kualitas dan Kuantitas Air Mani Sapi Friesian Holstein di Balai Inseminasi Buatan Singosari. Skripsi. Fakultas Kedokteran Hewan Universitas Airlangga. Surabaya. 82.

Wulandari. 2015. Karakteristik Performans Sapi Madura Karapan di Kabupaten Sumenep pada Kelompok Umur Berbeda [Skripsi]. Fakultas Peternakan Universitas Brawijaya. Malang. 87. 